\title{
Archaeological Culture Interpreted by Chinese Archaeologists
}

\author{
Zi Yan \\ School of History and Culture, Sichuan University, China
}

\begin{abstract}
Chinese modern archaeology has inherited the achievements of local epigraphy and modern western archaeology for decades, it has also achieved fruitful results. Whether at home or abroad, in the past or now, archaeological culture is one of the core issues widely discussed and studied in the process of archaeological development. Although it has been criticized, it has actually made many contributions to archaeology. Its importance is self-evident, and it is necessary to discuss and study. This paper will try to summarize the discussion of Chinese archaeologists on archaeological culture for combing, including it's definition, naming, interaction and dissemination.
\end{abstract}

Keywords: Chinese archaeologists, Archaeological culture, Definition, Naming, Interaction and dissemination.

\section{Definition of Archaeological Culture}

Since the Neolithic age, the scope of people's activities has expanded, the production technology and the ability to conquer nature have improved, and the number of effective data unearthed in field excavation has also increased. The previous staging system has been challenged, it is necessary to introduce new concepts to analyze and study cultural relics. So, in the 1860 s, the French archaeologist Mortier divided the European Paleolithic age into five periods and named it after the site first discovered, following the method of geological history stages in geology. At the same time, due to China's vast territory and complex and diverse natural environment, people who produce and live in different times and regions have different lifestyles, and their means of production and life also show many differences, forming a rich and diverse cultural outlook, which needs to be correctly and scientifically included and distinguished. Therefore, archaeological culture, the basic concept of modern archaeology, was first put forward by German archaeologist Kosina in 1911. In 1927, 16 years later, Mr. childe, a British archaeologist, put forward that we found that certain forms of remains - containers, tools, decorations, burial systems and house structures - often appear together. This complex with regularly connected characteristics should be called a cultural group or a culture. He believes that an archaeological culture should meet three elements: time, space and characteristics. Childe's definition of the meaning of archaeological culture has aroused extensive discussion in archaeological circles all over the world, and Chinese archaeologists have carried out a large-scale and long-term in-depth discussion on this issue in combination with their own actual situation and archaeological materials.

As an archaeologist who introduced the concept of archaeological culture into China for the first time, after considering the specific situation of Chinese archaeology, $\mathrm{Mr}$. Xia Nai believes that archaeological culture represents the community observed in archaeological relics (especially primitive social relics).At the same time, he further proposed that archaeological culture must have three conditions: a culture must have the characteristics of "a group", the characteristics of a group of people together are best found in more than one place, and there must be sufficient knowledge of the content of this culture. This definition is called the "three elements" of archaeological culture, which lays the foundation for Chinese archaeologists to study archaeological culture and has a far-reaching impact on later archaeological circles.

In the 1980s, Mr. Yan Wenming defined archaeological culture more clearly. He believed that archaeological culture specifically refers to the sum of physical relics existing in a certain period, a certain region and with certain characteristics. At the same time, he further expounds the composition of archaeological culture. He puts forward that archaeological culture should include at least five parts: settlement form, tomb form, production tools and weapons, living utensils and decorations, works of art and religious utensils. He also considered the level of archaeological culture and divided the archaeological culture itself into many levels: He regards "culture" as the first level, and its lower stages are called "types", as the second level; The "types" can be divided into "stages", and each small "stages" period can be divided into "zones" as the third level. Mr. An Zhimin, who was in the same period with him, holds that archaeological culture refers to a group of remains belonging to the same era, distributed in common areas and with common characteristics that can be observed in archaeological discoveries.

In 1986, Mr. Zhang Zhongpei published an article "several problems to be discussed in the study of archaeological culture", which proposed that archaeological culture is an archaeological remains with a certain period, a certain range and certain characteristics. He proposed that the key to naming archaeological culture is "typical remains". It's not hard for us to find out that his views coincide with the views of "community" and "group characteristics" put forward by Mr. Xia Nai, and his definition of "typical remains" is: Firstly, the remains have a certain scale in age and region, and the preservation of the remains is good; Secondly, the remains have qualitative stability in age and region, rather than those transitional remains; Thirdly, archaeological work has a certain quality and scale. He clearly advocated that the 
transitional remains in time or region should not be regarded as the "typical remains" of archaeological culture. This formulation further supplemented and improved the definition of archaeological culture and became the consensus of Chinese archaeologists from generation to generation.

It can be seen that the definition of archaeological culture represented by Mr. Xia Nai has been widely accepted for a long time. At the same time, it has been innovated and developed on the basis of field practice and theoretical research.

\section{Naming of Archaeological Culture}

In 1959, Mr. Xia Nai published the article "On the naming of archaeological culture", proposing that archaeological culture should be named after the small place names of typical relics discovered for the first time (such as Yangshao Culture); Or it is named after a region or watershed, which is named after the general scope of the distribution area of this culture has been made clear afterwards (such as Danube Culture); There are also things named after the characteristics of a culture (such as painted pottery culture); In the late primitive society, it was sometimes named after the clan names in written records (such as Bashu Culture).At the same time, he stressed that we should pay attention to the difference between "culture" and "period", "archaeological culture" and "culture". He also listed many requirements for naming: A culture must have a group of characteristics (the so-called characteristics are not necessarily have to be the most important things, this group of characteristics are not available in other cultures, and the type of characteristics should be a clear type); It is better to find more than one common group of types (only when more places find the remains of this culture, can we know its distribution scope and realize what is its main content, so we can determine the limit of content variation of this culture);We must have sufficient knowledge of the content of this culture and make a realistic and scientific analysis of the ancient cultural relics. However, it should be noted that $\mathrm{Mr}$. Xia Nai had not made a specific explanation on the quantification of the utensil group at that time, and there was still room for discussion on the naming method.

Therefore, with the further development of archaeology in China, Mr. Zhang Zhongpei put forward in his article "several problems to be discussed in the study of archaeological culture" published in 1987 that the key to the naming of an archaeological culture is the "typical remains", that is, the age and region of the remains have a certain scale and the preservation of the remains is good; The remains have qualitative stability in age and region, rather than those transitional remains; Archaeological work has a certain quality and scale. These above three standards are integral and indispensable. Mr. An Zhimin believes that according to the practice of archaeological research, it is generally named after the typical sites or characteristic relics and relics found at the beginning; There is a conventional question as to whether the name is appropriate or not-in principle, the naming of archaeological culture is limited to the community in prehistoric times, and historical remains can generally be named by the period. He also discussed culture and types, the so-called culture prefixed with "first", "before" and "after", and the three pairs of relations between culture and nationality. He believes that an archaeological culture includes many cultural factors, such as several specific types of housing, tomb system, pottery, tools and decorations. The two archaeological cultures may have many same factors, but there must be a series of unique "standard artifacts". Behind every culture, there is a common cultural tradition. Because of people's subjective initiative, the scope of culture is not necessarily completely consistent with the natural geographical division. A culture has different stages in the development process, and the scope of each stage is often different. For naming, as long as the meaning is clear, do not change it easily, but once it is easy to cause confusion, it must be adjusted.

In the same year, after reviewing the discussion process of archaeological culture naming in China's archaeological circles in the 20th century, Mr. Wang Renxiang put forward this view: when naming a new archaeological culture, what needs to be considered most is its essential characteristics, and the temporal and spatial framework can and should be gradually established in future research. Whether to choose the first discovered site or a typical site depends on whether the selected site reflects the basic characteristics of the archaeological culture to be named. He tried to use the "naming confirmation" procedure to prevent the proliferation of archaeological cultural naming.

However, in recent years, some researchers have put forward negative opinions on the practice of naming archaeological culture based on typical sites. For example, Mr. Zhang Guoshuo published an article "on the naming method of archaeological culture", which commented on various naming methods of archaeological culture, considered that it "violated the most common international principle of naming archaeological culture based on the place of initial discovery", and put forward several specific opinions: Firstly, adhere to the naming of the site discovered for the first time and avoid naming it as a "typical site". The condition is that the site must be officially excavated scientifically, and it should also be the earliest published site. Secondly, several archaeological cultures were found at the same site for the first time, using the "place name plus division naming method", such as the upper culture of XX, the lower culture of XX, etc. Thirdly, archaeological culture should be named according to the times or family names, which should be strictly limited to the scope of historical archaeology. Fourthly, abandon the naming method based on regional or cultural characteristics, and do not use double naming. He holds the point that typical sites and sites discovered for the first time are two different concepts, and there are often conflicts in their selection when naming them. More importantly, the selection of typical sites is difficult to grasp. The typical sites identified by different scholars are often different, and the naming will not be consistent. In fact, a truly typical site is difficult to find, and the first discovered site is generally not "the most representative", so it is not necessary to be strict with typicality and representativeness, nor can the archaeological 
cultural name be constantly changed with the discovery of more typical sites.

It can be seen from the research on the naming of archaeological culture by the above Chinese archaeologists that since the concept of ancient culture was introduced into China, China's archaeological circles have never stopped thinking about it. At present, archaeological culture can not be easily defined and named by simple principles and conditions. It is a complex multi-layered cultural aggregate. At the same time, after several generations of archaeologists' continuous thinking and exploration of archaeological culture, it has become an important part of Archaeology and one of the important theoretical methods.

\section{Discussion on the Interaction and Dissemination of Archaeological Culture}

Archaeological culture is a material reality, which must have its emergence, development and extinction process. At present, archaeological culture is in its development period, and its interaction and dissemination have also aroused the discussion of many domestic scholars.

Mr. Su Bingqi selected typical materials from the materials unearthed in the sites in various regions, made clear the ancient cultural features and mutual relations in various regions, and summarized them into several cultural systems based on the similarities and differences of their cultural connotation in a large region on the basis of accurate division of cultural types. Different cultural systems may have the same parts due to cultural communication and exchange; The same culture may also develop into different types. We can't simply think that there is a replacement or inheritance relationship between some cultures because they are in the same area. We should make a reasonable inference based on the stratigraphic relationship and the unearthed materials; Even several cultural origins in the same region may be different. It is not easy to classify the cultures of adjacent regions as homologous, nor simply understand the local culture as the dissemination of foreign culture because of its similarity with the culture of a certain region at the same time; There are also strong and weak points among cultures. Area is a block, which is a horizontal spatial distribution; The system is a strip, a vertical time relationship; Type is a branch of culture.

Mr. Li Boqian believes that the essence of archaeological culture is movement, it has its own antecedent culture and subsequent culture. During its existence, there are often other archaeological cultures around it. Therefore, it is very common for it to interact with other archaeological cultures in the process of its emergence, development and even decline. Before studying the interactive relationship, we must first determine its stage and age; Secondly, we must look at this issue from the perspective of development; Then we should study the interactive relationship on the premise of analyzing the cultural factors of archaeological culture; Finally, in the case of social stratification, we must study the archaeological culture comprehensively reflected on it on the basis of social structure analysis. In his opinion, the interaction between archaeological cultures may be fast or slow, strong or weak, active or passive, and there is no vacuum. From the perspective of strong culture, it may assimilate or even replace weak culture, and it may also lead to the emergence of new culture; From the perspective of weak culture, the policy of assimilation substitution is fully resisted, but it is treated separately in peaceful exchanges; When the archaeological cultures with equal strength expand to the same area, they often form a multi-cultural intersection area. Interaction is mainly in the form of cultural communication. Direct cultural communication generally retains the appearance of more original culture, and even appears "cultural enclaves" (small blocks of another archaeological culture within the distribution range of one archaeological culture); The dissemination through intermediary screening and transformation generally changes greatly and takes a long time, resulting in the phenomenon of "cultural lag", the dissemination of production technology is fast and far, while the dissemination of ideology is not so smooth. When the social evolution develops to the stage of stratification, archaeological culture will still maintain a unified appearance, but there will inevitably be a division between the upper and lower levels.

Mr. Tian Mingli believes that the spread of archaeological culture, it refers to the mutual influence, infiltration, integration and diffusion of cultural factors between different archaeological cultures. It is a process in which a cultural group borrows cultural elements from another cultural group and integrates into its own culture on the basis of maintaining the relative stability of archaeological culture. Communication is one of the essential attributes of archaeological culture, and its driving force lies in the human community, the creative subject of archaeological culture. Two basic conditions are needed to realize communication: the communication subject and the communication receptor are roughly the same or equivalent in age; The spatial location is appropriate, and there is no insurmountable geographical obstacle between the main receptors of transmission. At the same time, he put forward several ways of cultural communication: reference or imitation, trade or exchange, intermarriage, plunder or war, tribute or reward, individual or individual family migration and non permanent movement of sporadic population. The results of archaeological cultural migration are restricted by many factors, so there are often great differences.

Therefore, the differences and uniqueness of archaeological culture are caused by a variety of influencing factors. In the research process, we should not only pay attention to some aspects, but should study archaeological culture from a more comprehensive and multidimensional perspective. When discussing issues related to archaeological culture, Mr. Wang Wei noticed that there are several tendencies in the study of archaeological culture in China: Focusing on a certain kind of relics, the grasp of the overall appearance of archaeological culture is quite weak. Such as over reliance on pottery as the basis for classification; Paying too much attention to the existence of a certain kind of remains, and lack of quantitative 
analysis of archaeological remains; Pay attention to the analysis of the shape of utensils, and pay insufficient attention to the reasons leading to the characteristics of these shapes; Pay attention to the artifacts themselves, and pay insufficient attention to the research on the function of relics; Keen on naming new archaeological culture, competing for "naming right" and so on......He also mentioned that the study of archaeological culture is not limited to the study of a certain kind of artifacts, but also includes the study of various remains contained in archaeological culture, the study of genealogy, and the study of people's spiritual world and social structure and their relationship with other groups through these archaeological cultural remains, And the study of various factors leading to the development and change of archaeological culture and their roles. These problems are worthy of our future study and Research on archaeological culture.

\section{Summary}

It has been more than 60 years since it was introduced in the 1950s and 1960s. A stone stirs thousands of waves, Chinese archaeology has never stopped discussing archaeological culture. It can be seen that it is long-term and necessary to continue to use and develop the basic concept of "archaeological culture". But at the same time, it should be noted that we should not only be satisfied with the understanding of the basic appearance, age and pedigree of archaeological culture, but also understand the functions and functions of relics and relics through careful analysis of the connotation of archaeological culture, and explore the internal social conditions and cultural traditions reflected by this culture, These studies must be based on the correct identification and establishment of archaeological culture. We believe that the Chinese archaeological society continues to grow in the spiral cycle of discussion, establishment, overthrow and re-discussion, and the archaeological culture will be a dazzling star in the stars of archaeology!

\section{References}

[1] Xia Nai. On the naming of archaeological culture. Archaeology[J]. 1959 (04).

[2] Yan Wenming. Two problems in Neolithic archaeological research[J]. Cultural Relics, 1985 (08).

[3] An Zhimin. Archaeological culture. Encyclopedia of China - archaeology[M]. Encyclopedia of China Press, 1986.

[4] Wang Renxiang. Naming principles and procedures of archaeological culture[J]. Cultural Relics Quarterly. 1999 (03).

[5] Zhang Guoshuo. On the naming method of archaeological culture $[\mathrm{J}]$. Cultural Relics of the Central Plains, 1995 (02).

[6] Su Bingqi, Yin Weizhang. On the floristic types of archaeological culture[J]. Cultural Relics, 1981 (05).

[7] Li boqian. Research on the interaction between Archaeology and culture[J]. Southern Cultural Relics, 2008 (01).

[8] Tian Mingli. Dissemination and migration of archaeological culture $[\mathrm{J}]$. Cultural Relics of the Central Plains, 2001 (03).
[9] Wang Wei. Discussion on archaeological culture and related issues[J]. Archaeology, 2014 (12).

[10] Yan Wenming. Theory of archaeological culture. Archaeology towards the 21 st century[M]. Sanqin Publishing House, 1997.

[11] Chen Chun. Archaeological theory[M]. Fudan University Press, 2004. 